\title{
ICONICIDADE COMO ALTERNATIVA DE EXPLICAÇÃO PARA A HIPNOSE DE MILTON ERICKSON ${ }^{1}$
}

\author{
Iconicity as an Alternative Explanation of Milton Erickson's Hypnosis
}

\author{
Iconicidad Como Alternativa de Explicación para la Hipnosis de Milton Erickson
}

MAURícIo S. NEUBERN Hugo Nogueira Gonçalves

\begin{abstract}
Resumo: O presente trabalho busca propor uma alternativa de explicação para a hipnose de Milton Erickson (1901-1980) a partir da noção semiótica de iconicidade, que consiste na capacidade dos signos em transmitir qualidades de seus objetos. Neste trabalho, a possibilidade de explicação será desenvolvida, a partir de uma ilustração clínica de Erickson, em torno da discussão sobre três questões principais: a heterogeneidade da experiência hipnótica, a temporalidade e o papel do eu face às influências do inconsciente. Ao apontar as diferentes potencialidades lógicas dos signos, a iconicidade oferece subsídios de grande pertinência para compreender a diversidade do tecido vivido que compõe a experiência hipnótica, a presentificação da experiência de tempo e as diferentes formas de inserção e relação do eu quanto ao universo inconsciente que o precede. Nesse sentido, as contribuições daí consequentes são de grande pertinência para favorecer o afastamento de uma lógica puramente tecnicista da obra de Erickson, como também debates e apropriações coletivas em torno da mesma, condições necessárias para seu progresso como proposta de pensamento e terapia. Palavras-Chave: Hipnose; Semiótica; Psicologia Clínica; Milton Erickson.
\end{abstract}

\begin{abstract}
This study's intent is to propose an alternative explanation for Milton Erickson's (1901-1980) hypnosis from the semiotics notion of iconicity, which consists on the capacity of signs to transmit qualities of its objects. In this study, the possible explanation unfolds from a clinical illustration of Erickson into a discussion addressing three main subjects: the heterogeneity of the hypnotic experience, the temporality, and the roles of the ego acing the unconscious influences. By pointing the different logical potentialities of signs, iconicity offers subsidies of great pertinence to comprehend the diversity of the living fabric which composes the hypnotic experience, the presentification of time experience, and the different forms of insertion and relation between the ego and the unconscious universe that precedes him. In that sense, the consequent contributions are of great pertinence, favoring a purely technical logic with its debates and surrounding collective appropriations to move away from Erickson's work, necessary conditions for its progress as proposal of thought a therapy. Keywords: Hypnosis; Semiotics; Clinical Psychology; Milton Erickson.
\end{abstract}

Resumen: El presente trabajo propone una alternativa de explicación para la hipnosis de Milton Erickson (19011980) a partir de la noción semiótica de iconicidad, que consiste en la capacidad de los signos para transmitir cualidades de sus objetos. En este trabajo, la posibilidad de explicación será desarrollada, a partir de una ilustración clínica de Erickson, en torno a la discusión sobre tres cuestiones principales: la heterogeneidad de la experiencia hipnótica, la temporalidad y el papel del yo frente a las influencias del inconsciente. De este modo, al señalar las diferentes potencialidades lógicas de los signos, la iconicidad ofrece subsidios de gran importancia para comprender la diversidad del tejido vivido que compone la experiencia hipnótica, la presentificación de la experiencia del tiempo y las diferentes formas de inserción y relación del yo en cuanto al universo inconsciente que lo precede. En ese sentido, las contribuciones consecuentes son de gran importancia para favorecer el alejamiento de una lógica puramente tecnicista de la obra de Erickson, así como debates e apropiaciones colectivas en torno a la misma, condiciones necesarias para su progreso como propuesta de pensamiento y terapia. Palabras claves: Hipnosis; Semiótica; Psicología Clínica; Milton Erickson.

\section{Introdução}

Milton Erickson, psiquiatra norte-americano (1901-1980), foi um dos autores mais criativos e eficazes da psicoterapia e, particularmente, da hipnose do século XX. Seu legado foi um dos maiores responsáveis pela retomada de interesse pela hipnose, ao mesmo tempo em que trouxe contribuições de grande pertinência às terapias sistêmicas, breves e narrativas (Zeig, 2014). Opondo-se a uma lógica linear e autoritária de endereçar sugestões hipnóticas a uma pessoa, ele propôs um contexto indireto por meio de metáforas, analogias, contos de histórias e jogos de palavras que trariam o sujeito a um papel mais participativo e com um leque maior de liberdade na construção de seus processos (Erickson \& Rossi, 1980).

Crítico às tendências universalistas de psicoterapia, com noções e conteúdos gerais sobre como deveriam ser as pessoas e os processos terapêuticos, Erickson (citado em Neubern, 2009) tomou cada pessoa como ser singular numa proposta radical em que cada contexto terapêutico deveria ser traçado sob o intuito de contemplar suas características e 
modos de ser particulares. Numa perspectiva altamente humanista e pragmática (Neubern, 2009), concebeu que as diferentes expressões do sujeito (resistência, sintomas, emoções, ideias, comportamentos) poderiam ser utilizadas a favor da terapia seu princípio da utilização - e que não haveria uma forma padrão de transe, pois cada pessoa possuiria suas próprias formas de mergulhar neste estado ideia central de sua hipnose naturalista (Erickson, 1981). Em suma, o estado de transe seria um momento especial de emergência de potencialidades, aprendizados e recursos que, se acessados devidamente no contexto terapêutico, seriam capazes de levar o sujeito à resolução de seus problemas.

No entanto, o movimento ericksoniano, fundado não por Erickson, mas por seus discípulos, é marcado por concepções nas quais as ideias desse autor não seriam passíveis de explicação científica. Colocado no papel de um típico mestre fundador, aquele que tem seu nome e suas ideias tomados para fundar uma escola de psicoterapia (Stengers, 2013), frequentemente é concebido como uma espécie de mito ou visionário inacessível ao humano comum, alguém cujas ideias e ensinamentos jamais poderiam ser fielmente transmitidas e compreendidas. Aos interessados em aprender e praticar seus ensinamentos inovadores nada mais restaria que um mero aprendizado técnico, fosse pela forma como se compreendeu entre os adeptos a sua rejeição sistemática em adotar as propostas modernas de teoria, fosse pela impossibilidade em acessar a inteligibilidade de ideias tão profundas.

Embora a literatura sobre este ponto seja escassa, é possível listar algumas implicações de semelhante processo, principalmente por conta da acentuada separação entre clínica e pesquisa que parece caracteriza-lo (Neubern, 2017). Ao ser restrito a um legado puramente técnico, há um desprezo considerável de suas contribuições epistemológicas e teóricas, que são numerosas e relevantes (Bioy, 2017; Neubern, 2014; 2016a), mas ainda têm sido pouco comuns nos debates acadêmicos (Stengers, 2002). Suas teorias implícitas presentes ao longo de sua obra, suas bases epistemológicas pragmáticas e complexas, sua visão de homem e subjetividade pouco parecem interessar aos terapeutas, ao mesmo tempo em que se mantêm distantes do acadêmico. Assim, a obra desse autor é muito pouco presente em importantes espaços de formação, como as universidades, onde conta com raros professores que a conhecem e reconhecem sua pertinência, e menos ainda discutida entre os pesquisadores que parecem se voltar muito mais para perspectivas estatísticas e cognitivas quando o assunto é hipnose (Jensen \& Patterson, 2014). Há, portanto, a forte possibilidade na qual o autor mais relevante da retomada da hipnose torne-se um ilustre desconhecido de interlocutores importantes e necessários para a evolução coletiva de suas ideias e também que sua obra se descaracterize, seja pela falta desse tipo de reflexão e de pesquisa, seja pela apropriação indevida por movimentos e teorias pouco afins a suas propostas originais.

Desse modo, a proposta deste trabalho é a de oferecer uma alternativa de explicação sobre questões pertinentes da obra de Erickson que possam favorecer a discussão e consequente apropriação coletiva de interlocutores interessados na obra de Erickson. As questões aqui levantadas serão em torno da heterogeneidade do tecido da experiência, a temporalidade e o papel do eu frente às influencias do inconsciente, questões que perpassam as discussões de Erickson (Erickson \& Rossi, 1980) e outros pesquisadores da hipnose (Bioy, 2017; Neubern, 2016a; Zeig, 2014). As explicações inicialmente desenvolvidas terão como fio condutor a noção de iconicidade (Peirce, 1998), ou seja, a capacidade dos signos em transmitir as qualidades de seus objetos (Jappy, 2013; Nöth, 2015), sobretudo por favorecer uma concepção de práxis (Morin, 2014), que aproxima a construção do pensar (teorias, ideias e interpretações) às intervenções junto ao empírico (métodos, técnicas e instrumentos). Esta discussão será desenvolvida a partir da ilustração de um caso clínico de Erickson (1981), aqui destacado em seus pontos principais. Antes desta discussão, porém, serão ressaltados alguns dos princípios e conceitos semióticos e complexos que lhe servirão como fundamento para o termo iconicidade (Peirce, 1998).

\section{Pontos de Partida}

A ideia central deste trabalho é a de que a noção de iconicidade (Jappy, 2013; Nöth, 2015) sirva como um caminho explicativo pertinente para a compreensão da hipnose de Erickson, em termos de sua clínica do mostrar (Neubern, 2016a). Ao contar uma história assumir determinado papel na relação ou propor um jogo de palavras a seu paciente, Erickson não buscava dizer-lhe algo ou lhe propor a elaboração de um processo inconsciente, mas lhe apresentar uma forma semiótica que se assemelhasse simbolicamente a algum tipo de experiência por ele vivida, tanto nos problemas geradores de sofrimento, como nos recursos terapêuticos evocados. Assim, Erickson criava um contexto relacional em que as diferentes expressões (contos de histórias, papéis dramáticos, prescrições de tarefas, usos de palavras) assemelhavam-se às experiências de mundo do sujeito no tocante aos dilemas vividos, como também em sua potencialidade de mudança. Ao invés de se utilizar de comandos imperativos (como na hipnose tradicional) apresentava tais signos ao sujeito que eram capazes de desencadear mudanças de alta relevância terapêutica em seu universo, caracterizadas pela reconfiguração de seus processos psíquicos e comportamentais. Tal aproximação com o mundo do sujeito partia de duas ideias centrais (Erickson \& Rossi, 1980), sendo a primeira a da hipnose naturalista, isto é, o transe como uma experiência natural, singular e cotidiana das pessoas, não se adequando a modelos gerais. Já a segunda, seria a da utilização, na qual caberia ao terapeuta se utilizar das diferentes expressões do sujeito (comportamentos, resistências, modos de pensar, agir, sentir, falar) a favor de sua terapia, ao invés de criar um contexto padrão para cada sujeito ${ }^{1}$.

1 A dificuldade da reflexão e do estudo sobre a obra de Erickson se dá, 
A noção de hipnose aqui utilizada compreende um conjunto de processos de comunicação específicos e o estado de transe que dele decorre (Neubern, 2016b). O transe é caracterizado por uma espécie de descentramento do eu, isto é, um conjunto de alterações de suas referências nas relações com o mundo (espaço, tempo, causa, matéria, outro) que favorecem a emergência de uma série de processos inconscientes. Estes, geralmente inibidos ou inacessíveis ao eu durante a vigília, possuem considerável relevância terapêutica para a reconfiguração das experiências de sofrimento, podendo mesmo situa-lo em novos processos de relação com o mundo de sua subjetividade e o mundo social onde se insere. Eles também se referem a uma considerável polifonia que remetem a diferentes modos de relação do sujeito e a diversas maneiras de subjetivação de saberes e processos coletivos (Neubern, 2016b).

De um ponto de vista da comunicação, as palavras, gestos, entonações de voz e expressões do terapeuta consistem em signos (Peirce, 1998), isto é, aquilo que representa um objeto e cria um efeito (interpretante) na mente do interlocutor. Os signos podem se referir a este objeto qualitativamente (os ícones), por meio de relações físicas ou funcionais (os índices) ou ainda por lei, hábito ou convenção (os símbolos). Em termos hipnóticos (Neubern, 2016a; Nöth, 2015), adjetivos, verbos e advérbios e as imagens visualizadas constituem-se como ícones, assim como pronomes, vocativos e gestos que fixam a atenção do sujeito, índices. Os símbolos seriam as palavras em geral, especialmente os discursos e histórias utilizadas pelo terapeuta.

Seguindo-se a esta tricotomia, a experiência humana também é qualificada na fenomenologia de Peirce (1998) em três dimensões lógicas. A primeiridade consiste na experiência potencial, ainda não existente, do sentir que, de tão sutil, é plenamente presente. Consiste numa das bases fundamentais para se compreender o transe, notadamente por ser muito anterior e inapreensível ao eu. Já secundidade é concreta e singular, estando muito ligada aos processos de reação que ocorrem no transe, como na fixação de atenção que antecede as alterações de referência. E, por fim, a terceiridade, que remete a organização da experiência, implicando as leis e os hábitos, envolvendo o campo do pensar, embora este pensar também possa ir além do campo das deliberações conscientes do eu, envolvendo influências coletivas e culturais (Neubern, 2016b).

Esses conceitos são importantes para se conceber a iconicidade, que envolve, em larga medida, outro tipo de signos - os hipoícones ou ícones imperfeitos: as imagens, signos de primeira-primeiridade, que se referem a seus objetos por transmitirem as qualidades dos mesmos (as cores, formas das sugestões, ritmos, tons de voz, pausas); os diagramas, signos de segunda-primeiridade, que se referem a seus objetos por mostrarem as relações funcionais entre as partes de seus objetos (como as

principalmente, pela ausência de um corpo teórico com seus respectivos conceitos. Contudo, sua crítica às teorias vigentes, sua ênfase na potencialidade humana, na experiência individual e singular, permitem uma aproximação com o pragmatismo, cultural e em termos de visão de mundo, o que justifica a busca da obra de Peirce. descrições) e as metáforas, que justapõem num só signo dois campos distintos. Na expressão do caso a ser discutido, a expressão utilizada para se referir ao paciente, o "Harvey é um saco de tristeza", associa esta pessoa (o campo de um ser humano) a um objeto onde se depositam outros objetos (o campo de inanimado e instrumental) que abriga sentimentos (novamente o campo humano) com o intuito de buscar definir sua identidade.

Do exposto acima, é possível destacar ainda alguns conceitos básicos, associando hipnose e semiótica. Primeiramente, o eu consiste num conjunto de configurações semióticas que (Colapietro, 1989): a) remetem a trocas e práticas sociais anteriores; b) forma-se também a partir de uma dialética com o mundo, principalmente por processos de agenciamento; c) é um signo identitário, situando o sujeito via linguagem e subjetivação quanto a si e o mundo. Quando alguém se utiliza do pronome "eu" faz alusão a tais princípios; d) constitui-se em relações com o mundo por meio de referências (tempo, espaço, causa, matéria, outro) que permitem o sujeito partilhar da realidade consensual de uma cultura. É a alteração dessas referências que caracteriza o transe; e) implica na capacidade de reflexividade, ou seja, pensar a si, o que remete a uma condição simbólica. Em segundo lugar, a noção de inconsciente refere-se aqui a uma dimensão corriqueira de uso feito pelas pessoas, na qual algo escapa à deliberação racional dos sujeitos. Pode envolver desde um esquecimento despretensioso, a um conjunto de processos profundos e reprimidos, que se encontram distantes de sua deliberação ${ }^{2}$, dos quais o sujeito pode mesmo sequer desconfiar da existência.

Em terceiro lugar, subjetividade será aqui tomada como uma ótica semiótica e complexa (Neubern, 2016), ou seja, uma dimensão simbólica e emocional, organizada semiótica e fenomenologicamente, da experiência dos sujeitos. Ela articula dimensões distintas tradicionalmente opostas pelo paradigma moderno em Psicologia (interno x externo, determinação x autonomia, individual x coletivo, essência x existência), ao mesmo tempo em que se organiza de modo singular em cada sujeito, por meio de vários sistemas semióticos. Esse toque simbólico e emocional dos processos semióticos que caracteriza a subjetividade se faz presente tanto nos processos internos, como nas relações dos sujeitos e grupos (Colapietro, 1989).

\section{0 "Saco de Tristeza"}

Em uma demonstração frente a vários profissionais de psiquiatria e psicanálise céticos quanto à hipnose, Erickson (1981) procedeu a um transe altamente terapêutico junto a um jovem de pouco mais de 30 anos, chamado Harvey, que lhe pediu ajuda para encontrar um homem fora da condição

\footnotetext{
2 É certo que a noção de inconsciente demanda ainda maiores aprofundamentos de um ponto de vista das ideias de Peirce, inclusive em termos de sua fenomenologia, tarefa que ficará para mais adiante. Também é importante ressaltar que, embora Erickson se utilizasse sobremaneira deste termo, ele jamais o definiu conceitualmente. Daí o apelo às ideias de Peirce, tarefa que ainda se constitui num momento bastante inicial.
} 
de um "saco de tristeza". Ele vinha de uma demissão recente e sentia-se fracassado. O ponto inicial da demanda era a dor e seus sentimentos de inferioridade, que não lhe permitiam reconhecer suas potencialidades, como a inteligência e sua rica vida de fantasia. Então, Erickson lhe sugeriu que visualizasse algumas bolas de cristal ou telas nas quais ele poderia enxergar várias cenas de vida muito importantes, ao mesmo tempo em que ele se esqueceria de sua própria identidade, seu nome e sua idade: ele nada mais seria do que uma inteligência olhando tudo ao redor nas telas e na sala. Aos poucos, formou-se em sua mente a visão de um menino, que ele seguiu até a escola. Assistiu o menino ter sua mão batida pela palmatória do professor; em outra cena, viu o professor forçando-o a mudar a escrita da mão esquerda para a mão direita; em seguida, uma nova e severa punição do professor diante de todos.

Em outra cena, Harvey visualizou o menino retornando para casa muito triste e se surpreendeu com o suspense que esta cena parecia lhe antecipar: o menino chegando em casa e olhando pelo portão para o jardim e o xerife com uma arma em punho. Este acabara de atirar em seu cãozinho, levando-o a chorar muito. Erickson, assim, sugeriu-lhe que visualizasse novas cenas alguns anos depois e ele viu o mesmo menino, já com uma idade aproximada de 10 anos, sentindo-se muito mal por ter caçado um coelho na mata e, em seguida, com 15 anos, no alto de uma barragem abandonada, refletindo sobre as terríveis coisas que podem acontecer aos seres humanos. Aos 22 anos, esse mesmo menino, sentiu-se muito inferior ao ser recusado por uma garota. Esse mesmo jovem foi visto, em seguida, saindo muito triste de um tribunal, sentindo-se inferior após o divórcio e com muitas ideações suicidas. Na visualização seguinte, o jovem com 28 anos, foi demitido de um emprego do qual gostava e por volta dos 30 anos, sentindo-se um verdadeiro miserável.

Ainda em transe, Erickson pediu ao jovem que analisasse e lhe explicasse o que essas imagens possivelmente significariam para ele, o que deu espaço para uma conversação sobre a repetição de experiências traumáticas ao longo da vida. É importante salientar que Harvey não sabia que estas imagens se referiam a ele mesmo, e ele acrescentou que, se tais acontecimentos tivessem ocorrido consigo, provavelmente buscaria o suicídio. A conversa foi finalizada com uma sugestão pós-hipnótica na qual Harvey poderia escrever claramente após voltar do transe. Após tal conversação, Erickson lhe pediu que escrevesse uma frase: "Hoje é um belo dia de março". Ele saltou, como uma criança feliz, frente à audiência e falou com entusiasmo: "Eu posso escrever claramente. Eu posso escrever palavras legíveis!" Harvey passou o resto da noite gabando-se de sua clara e bela escrita, de maneira que Erickson lhe sugeriu que ele poderia aproveitar esse senso de orgulho pessoal e realização e aplica-lo a qualquer situação essencial de sua vida. Retornou a seu antigo emprego para uma entrevista com seu chefe, convencendo-o a readmiti-lo, aumentar seu salário e a ceder-lhe uma nova mesa de trabalho. Após sua readmissão, percebeu que um colega estacionava o carro em sua vaga e resolveu tomar uma atitude quanto a isso: esperou-o retornar e disse-lhe que ele sempre fizera aquilo, que ambos poderiam brigar seriamente, mas que ele preferia convidar o colega para uma cerveja para uma boa conversa. Ele também se mudou de casa, reformou o carro e passou a frequentar restaurantes melhores.

\section{Heterogeneidade Semiótica}

O primeiro ponto digno de questão é o papel da iconicidade numa compreensão complexa e heterogênea da materialidade que constitui a experiência da hipnose, seja na subjetividade do terapeuta e do contexto relacional, seja no que se refere ao que é vivido pelo sujeito em transe. No tocante ao terapeuta, é possível destacar que a concepção do diagrama é de grande valia para se ressaltar a capacidade de um clínico em captar o mundo do outro. O caso de Harvey é bastante ilustrativo nesse tópico uma vez que Erickson lhe permite montar o diagrama durante o transe e, respeitando sua própria sequência, apresenta algumas sugestões (como as reflexões, explicações e sugestão pós-hipnótica) que lhe trazem significativas diferenças. É interessante destacar neste processo que, malgrado o diagrama demande forte teor descritivo (Nöth, 2015), ele também implica um aspecto interpretativo, a inferência de Peirce (1998), pois refere-se a um mundo psíquico não acessível diretamente à observação.

Assim, o clínico, ao mesmo tempo em que percebe, registra e qualifica os signos visíveis a seus olhos, constrói, em seu pensamento, os elementos que pressupõem uma regularidade configurada como diagrama na subjetividade do sujeito em torno de um determinado tema. Ao mesmo tempo em que este processo necessita de precisão, ou seja, este diagrama precisa refletir de forma pertinente a experiência do outro, ele também demanda do clínico uma dimensão de experiência criativa largamente perpassada pela primeiridade (Neubern, 2016a). Tal dimensão, que aproxima a clínica de uma práxis estética, implica o afloramento de processos anteriores ao eu, que não o diluem e são inapreensíveis a ele, embora fundamentais em sua criação.

Ao se deparar com a emergência de semelhantes processos, ao invés de uma busca por apreensão, o clínico necessita de uma atitude que integra o "deixar-se envolver" e o uso de hipoícones para poder qualificar, de alguma forma, o que vivencia no momento, inclusive na relação com o sujeito. É nesse movimento duplo que ele possui condições de captar, em seu sentir, e gerar, em seus momentos reflexivos (que envolverem aqui uma terceira-primeiridade), uma forma de se endereçar ao outro que, de certo modo, parece refletir, profunda e pertinentemente, aquilo que é vivenciado por seu interlocutor. Cabe aqui uma analogia na qual o clínico se aproxima da figura do surfista que se deixa levar pelas ondas que o molham e envolvem, mas, longe de uma passividade absoluta, possui uma diretividade que o faz aproveitar os movimentos do mar a favor de seus propósitos. 
Boa parte de suas construções neste momento (sugestões, ideias e percepções), como as águas do mar, são fugidias e temporárias, pois são originárias daquele momento e do encontro com aquela pessoa singular. Elas podem lhe escapar entre os dedos caso tente se apropriar delas a fim de situá-las na condição de existente, com os sérios riscos de reificação e substancialização típicas das teorias modernas (Brito \& Pesce, 2015). Contudo, elas consistem em momentos fundamentais das relações humanas e da própria construção do saber, o que traz à tona a necessidade de que sejam qualificadas de alguma forma, como por meio dos hipoícones que, caso sejam respeitados em suas lógicas, ao invés de absorvidos em outros signos, serão devidamente situados na relação com os demais processos (Jappy, 2013; Neubern, 2016a): permanecerão como fundamento diáfano, sutil, fugidio, presente e potencial que permitem a emergência de outras formas semióticas mais complexas e concretas.

No que concerne a heterogeneidade semiótica da construção do transe, a iconicidade se situa como um campo rico em contribuições, dado que sua perspectiva não apenas rompe com as tendências de categorias hegemônicas tipicamente modernas, como ainda ressalta os papéis fundamentais dos sentimentos. Uma experiência como a de Harvey não poderia ser facilmente explicada por categorias uniformes como cognição, comportamento, narrativas ou significados, posto que, em cada momento, há uma diversidade de signos, que se fundam sob lógicas distintas, mas se articulam e configuram na construção dos mais distintos sistemas. A própria sequência de cenas que se verificam em sua mente e são por ele relatadas trazem uma riqueza considerável de imagens e diagramas que se organizam na composição de metáforas de grande pertinência para a compreensão de sua história e isso sem se levar em conta aqui as demais classificações semióticas ali presentes.

Semelhante perspectiva é de grande valia para a compreensão da subjetividade, pois destaca uma forma possível de se conceber a heterogeneidade que compõe seus tecidos que, frequentemente, tem sido silenciada pelas tentativas teóricas em compreendê-las e pesquisa-las (Morin, 2013; Neubern, 2016a). Ao se reduzir tal diversidade a um único foco explicativo, perdem-se não apenas a capacidade de acesso a especificidade de certos momentos dessa realidade, como ainda a compreensão das lógicas que as precedem e organizam. Ao contrário, de um ponto de vista semiótico (Jappy, 2013; Nöth, 2015), é possível considerar que, embora estejam todas presentes na influência e no transe, elas não se diluem entre si, uma vez que guardam suas raízes lógicas mesmo quando se integram à construção de sistemas subjetivos mais amplos. Assim, no momento em que Harvey visualiza a sequência de cenas, pode-se considerar certo predomínio de diagramas e imagens, ao passo que ao pensar, ainda em transe, a situação como se estivesse fora das cenas e refletir sobre suas implicações, parece haver predomínio das metáforas, pensamentos e hábitos, malgrado a antecedência semiótica de primeira e secundidade.

Esses dois momentos são muito pertinentes para se refletir sobre uma dicotomia comum entre as psicoterapias formada entre as abordagens voltadas para padrões, comumente associadas a terapias cognitivo-comportamentais, e as que enfocam o simbólico, mais relacionadas a abordagens psicanalíticas, psicodinâmicas e narrativas (Neubern, 2016a). Considera-se aqui que semelhante polarização deriva, em parte, das dificuldades que as teorias modernas encontram face à complexidade da experiência subjetiva, uma vez que buscam reduzir sua diversidade semiótica a categorias teóricas hegemônicas. Na perspectiva aqui proposta, deve-se ressaltar que essa polarização não possui razão de ser, mas precisa ser relativizada em referências lógicas específicas. Assim, as reações que compõem o diagrama da sequência de imagens (o que seria um padrão) apresenta um caráter reativo típico da secundidade, mas é também simbólica (Nöth, 2015), uma vez que envolvem processos constituídos na subjetividade de Harvey, compondo assim uma espécie de diagrama simbólico.

Já a reflexividade que desenvolve ao pensar as implicações das cenas em sua vida consiste muito mais num processo de mediação e produção de novos significados e narrativas, ou seja, algo próximo a uma legítima terceiridade. Em outras palavras, tanto padrões como narrativas envolvem processos simbólicos, embora estes se organizam distintamente em termos semióticos, conferindo maior ênfase na secundidade ou na terceiridade. A flexibilidade de um grande terapeuta como Erickson (Erickson \& Rossi, 1980) está exatamente na capacidade acurada em perceber esta predominância, de maneira a atender, com precisão, a necessidades específicas de determinados processos dos sujeitos por meio da criação de contextos e técnicas particulares para isso. Em ambos os casos, porém, ressalta-se a importância de uma percepção teórica capaz de estabelecer estas distinções e, sobretudo, qualificar o papel da iconicidade.

Este aspecto primeiro e potencial da iconicidade presente na influência hipnótica é, nessa perspectiva, decisivo para as alterações de referências eu-mundo que caracterizam o transe (Neubern, 2016b). É possível conceber que a iconicidade, sendo anterior ao eu, faça com que este deslize sutilmente de suas referências de tempo, espaço, matéria e causa (que caracterizam a realidade consensual) para inseri-lo num mundo diáfano e imaginário da primeiridade. Trata-se do mergulho num universo anterior, não em termos cronológicos, mas lógicos, caracterizado pela qualidade típica de experiências primeiras que, quando acessadas, podem favorecer reconfigurações de grande relevância em processos por elas sustentados. É possível conceber, nesse sentido, que o impacto em termos de primeiridade em Harvey é a base de sua mudança, que se estende também a outros momentos de sua experiência que incluem a reflexão e a tomada de novas atitudes, como a conversa com o chefe e a negociação com o colega abusivo.

Contudo, dessa amálgama de imagens, sensa- 
ções, formas, sons e cores emergem processos nos quais o eu pode ser projetado em outros seres ou pessoas e enxergar-se de fora (como no caso de Harvey), interagir com personagens culturais, como espíritos, daimons, deuses, orixás e santos (Clément, 2011; Nathan, 2015) e revisitar seus dramas de existência (Scheschner, 2013) de modo a produzir novos diagramas e metáforas capazes de sinalizar mudanças de considerável pertinência terapêutica para o sujeito. O ponto profundo de reflexão aqui destacado talvez se ligue à dimensão de profundidade típico da iconicidade (Nöth, 2012), posto que quanto maior o mergulho que o indivíduo promove em si, mais parece se acessar a considerável influência coletiva típica do transe (Morin, 2013). Disso decorre considerar que a primeiridade de alguma forma acessada não se constitui como tema importante apenas na constituição dos demais processos individuais complexos (Shore, 2016), mas principalmente na abertura que proporciona para a influência de poderosos dispositivos coletivos que são decisivos na fundação do sujeito, encontrando-se disponíveis durante o transe (Clément, 2011; Nathan, 2015). Trata-se de um caminho interessante para se superar a dicotomia moderna estabelecida entre o individual e o coletivo que tem caracterizado diversas escolas de psicoterapia (Gonzalez Rey, 2007) e mesmo de hipnose (Clément, 2011).

\section{Temporalidade}

Este tema não passa despercebido a Erickson (Erickson \& Rossi, 1980) que, de modo pioneiro, propõe uma concepção integradora na qual o sujeito poderia aprender com seu passado, vivenciar seu presente e se dispor a um futuro sob novas perspectivas, como bem ilustrado no caso de Harvey, quando lhe solicitou que pensasse nas implicações daquelas cenas em sua vida e se dispusesse a viver de outro modo. Não se trata aqui de um tempo cronológico, mas de uma experiência vivida na qual o passado e o futuro estão vivos e atuantes no presente do sujeito. Numa ótica não distante de algumas propostas existencialistas (Binswanger, 2008; Minkowski, 2014), preconizou que o sujeito se concebesse num todo que presentificasse seu passado, de modo à reconfigurá-lo, e seu futuro, cujos projetos seriam altamente estruturantes, em termos de sentidos para a vida.

É justamente neste ponto - a presentificação - que a iconicidade pode ser concebida nos propósitos aqui destacados. Isto porque a questão importante não é apenas a explicitação técnica de como proporcioná-la, mas uma maior clareza conceitual que favoreça um melhor entendimento de diferentes modos de presentificação por meio da iconicidade. As imagens, por exemplo, com todo seu frescor de primeiridade evocam, sobremaneira, o presente imediato, algo sobre o qual só se pode viver sem pensar, sob a pena de perder esta experiência. No sentido aqui levantado (Nöth, 2015), as imagens referem-se às qualidades específicas da hipnose (gesto, cores, cenas, tom de voz, pausas) numa experiência de absorção do sujeito capaz mesmo de fazer com que se esqueça de si naqueles eternos minutos, como se deu com Harvey. Em uma palavra, as imagens ocupam o lugar de um presente presentificado (a primeira-primeiridade) que consiste no momento mais radical do transe, em que o sujeito se entrega quase que por completo ou, como no termo extasis, fica fora de si. Por se tratar de algo amplamente potencial, pode servir como uma experiência de grande valor terapêutico, na qual o sujeito se desvencilha de ideações negativas que, como em Harvey, o paralisavam e faziam sofrer, para acessar uma qualidade intensa de sentimentos que o impulsionam à mudança.

Já os diagramas, que remetem a uma segunda-primeiridade, implicam reações que não ocorrem de forma aleatória, mas em função de experiências anteriores que, em algum nível, as determinam. Talvez esteja aqui a explicação do grande diagrama negativo de Harvey, composto por cenas que apenas confirmavam um passado negativo. Assim, os processos históricos são, a bem dizer, retratados naquele instante, compondo uma junção do passado com o presente colocada frente aos olhos do sujeito por meio de diagramas. No entanto, os diagramas em Erickson não deixam de possuir um teor simbólico que faz com que a evocação da experiência das pessoas não se dê por ordens, mas pela semelhança (típica da iconicidade) que não é explícita entre o que é mostrado pelo terapeuta e o que é vivido pelo sujeito. Isso favorece ao sujeito uma posição mais livre e participativa durante o transe, pois não se vê constrangido por ordens, nem ameaçado pelos processos de sofrimento que o levam à terapia.

Nesse sentido, o diagrama utilizado terapeuticamente sempre acrescenta algo de diferente quanto à sua dominância negativa. Quando o terapeuta acrescenta algo numa sequência, como a frase "Hoje é um belo dia de março", o sujeito tem algo novo de sua própria experiência evocada na composição deste novo e diferente arranjo, que modificará, de maneira bastante significativa, os diagramas originais do sofrimento. Se o passado é ali presentificado ele também traz potencialidades diversas favoráveis a novos processos de configuração, comumente ignorados ou marginalizados pelo sujeito. Tudo se passa como se o terapeuta, numa comunicação subliminar, mostrasse ao sujeito vários focos sequenciais de seu sofrimento para, em seguida, mostrar-lhe também, em diferentes momentos dessa sequência, episódios, habilidades, sentimentos, cenas e possibilidades sob vários ângulos distintos da dominância negativa em sua subjetividade.

Vale também destacar que a cena deste processo terapêutico repete iconicamente uma das cenas significativas visualizadas por ele, obtendo, porém, outro tipo de desfecho. Assim, é possível conceber que: ele (antes, uma criança), estava numa sala de outros aprendizes profissionais (na época, outros alunos), sob a exposição de um professor, Erickson (na cena original, o professor escolar). Contudo, ao invés da humilhação pública frente aos colegas, como o fez o professor na escola, Erickson lhe apontou uma saída produtiva com a frase escrita ao final e Harvey foi acolhido pelos presentes, de ma- 
neira que um diagrama novo repetiu o passado, mas acrescentou diferenças marcantes sobre ele, criando um desfecho distinto da exposição vexatória e ajudando Harvey a processo de mudança muito significativo.

Por outro lado, as metáforas, profundamente ligadas aos hábitos, consistem em formas semióticas de terceira-primeiridade, na qual o futuro é vivido no agora, como se uma lei subjetivada pelo sujeito antecipasse suas formas de pensar, sentir e agir frente aos acontecimentos da vida. Essa lei, eminentemente simbólica, pode derivar de uma série de influências socioculturais que se organizam, em seu mundo, como mandatos familiares, papéis e missões capazes de leva-lo a vivenciar dramas repetitivos ao longo da vida ou mesmo ao cumprimento de certas profecias sociais e familiares. Não sem razões, Harvey se definia como um "saco de tristeza", isto é, por meio de uma metáfora, na qual os acontecimentos negativos surgiam em seu caminho ou seriam atraídos por ele, confirmando sua sina de ser uma pessoa infeliz, marcada por vivências traumáticas e tristezas.

Neste sentido, trazer signos de terceira-primeiridade para o presente, jamais deve significar uma doutrinação voluntária e consciente para novas atitudes, mas um processo de reconstrução profundo, de dentro para fora, que envolve a temporalidade vivida como um todo. Há aqui a potencialidade do presente (como nas imagens e os sentimentos que evocam), os novos arranjos que ordenam as vivências do passado (típicos dos diagramas) e uma nova forma de se posicionar frente ao porvir (característico das metáforas). Logo, quando Erickson pediu a Harvey que pensasse sobre o que significariam as cenas visualizadas, ele não lhe propôs uma metáfora, mas proporcionou um contexto favorável à sua criação: ao mesmo tempo em que houve, durante o transe, um processo ativo e intencional do eu em pensar de outra forma, este eu foi cercado numa atmosfera simbólica e emotiva promovida pelos diagramas, evocando processos que o antecederam e nutriram a partir de recursos profundos com amplas possibilidades criativas. O que emergiu daí foi presentificado em termos de uma terceira-primeiridade, fazendo com que o sujeito voltasse seus olhos para o futuro e se posicionasse sob novas metáforas, em suas formas de pensar, sentir e agir.

É desse jogo complexo entre consciente e inconsciente que nascem as metáforas, jogo este que se repete em dramas e legados familiares, dispositivos socioculturais, missões espirituais, em suma, em importantes momentos das práticas humanas (Lakoff \& Johson, 2003). Nesse sentido, seria possível conceber se a própria psicoterapia, e toda uma série de representações sociais a seu respeito, não seria ela mesma uma potente oficina de metáforas capaz de fazer com que os sujeitos produzissem novos processos simbólicos para si, os outros e a própria vida (White, 2007). Não sem razões, a associação da hipnose ao mágico, ao espiritual e ao extraordinário (Bioy, 2017; Clément, 2011) pode promover processos muito eficazes na construção de novas metáforas, assim como o próprio Erickson, cadeirante e de personalidade excêntrica, utilizou-se sobremaneira de suas condições pessoais para inspirar significativas mudanças simbólicas em seus pacientes e alunos (Zeig, 2014).

\section{O Eu e as Influências Inconscientes}

O terceiro ponto a ser levantado e debatido coletivamente refere-se às próprias relações entre o eu e os processos que o antecedem, concebidos como inconscientes. Num primeiro momento, é importante destacar que a comunicação subliminar que acontece entre duas pessoas na hipnose encontra na noção de signo (Peirce, 1998) um princípio de grande relevância. Isto porque, ao mesmo tempo em que faz referência a algum objeto, ele possui um substrato material (como a voz, o som, a imagem) que adentra na experiência de um outro, gerando o interpretante. Mesmo que não haja uma linearidade neste sistema (Bergman, 2009), a noção de signo favorece as possibilidades lógicas de relação entre aquilo que é mostrado ao sujeito num processo relacional e o que é subjetivado por ele. Como este sujeito não é passivo, ele procederá à sua própria semiose, isto é, produzindo novos signos atrelados a sua vivência hipnótica. Por esta via, é possível conceber uma pesquisa clínica (Neubern, 2017) que transcenda a polarização externo-interno sem dilui-la e situe a interpretação do terapeuta como uma condição fundamental na compreensão desse complexo jogo de formas semióticas que ora aparecem na arena relacional por meio dos signos, ora só se dão a entender sutilmente na produção dos interpretantes.

A iconicidade aparece aqui tanto na configuração de signos presentes na comunicação, como naquilo que é evocado, em termos profundos, dos sentimentos inconscientes da experiência do sujeito. E, como esta experiência possui diferentes formas de agenciamento (Gallagher, 2012), a iconicidade parece se constituir como uma forma privilegiada de comunicação com a pluralidade destes processos, acessando-as por diferentes vias do mostrar que a caracterizam (como os hipoícones). Assim, durante o transe, o eu pode se deparar com outras formas semióticas, como o tu, o ele, ela, isso, nós, eles (Morin, 2013) num palco que privilegia o mostrar em processos de comunicação altamente perpassados pela iconicidade. Harvey visualizou várias cenas com outras pessoas como se fossem da vivência de um outro, cenas que não lhe foram explicadas, mas mostradas, e que possuíam significados específicos que, de modo subliminar, mobilizaram-no intensamente.

Tem-se aqui não apenas as possibilidades de acesso e negociação a tais dimensões durante o transe, como ainda as perspectivas de compreensão de como as influências coletivas passam a habitar e povoar as experiências individuais, em processos muito anteriores à constituição do eu. Isto pode ser observado em situações como a de Harvey que, provavelmente, por meio de várias formas de relação depreciativas, assumiu para si a metáfora do "saco de tristeza", fenômeno que, mesmo contando com 
as ações e construções decisivas do sujeito, foi também profundamente engendrado pelos modos de vidas dominantes numa dada sociedade, permeados por processos econômicos, familiares, políticos, trabalhistas, de pertencimento social, étnico e religioso (Morin, 2013). Não seria exagero afirmar que a fabricação de um "saco de tristeza", que traz em si a figura do fracassado, foi construída numa sociedade que privilegia o sucesso e a felicidade pessoal, como a norte-americana. Tal processo foi intensamente forjado por diferentes vias de comunicação (interpessoais, institucionais, trabalho, cinema, TV) no qual a iconicidade possuiu um papel central.

Por outro lado, a iconicidade encontra-se também no centro de uma relação, por vezes polarizada nas psicoterapias (Gonzalez Rey, 2007), entre as determinações inconscientes e as formas de autonomia do eu. Isto porque tanto as ações deliberadas do eu, como os processos que, como no caso de Harvey, parecem se impor a ele e escraviza-lo possuem bases comuns nos sentimentos profundos que podem ser acessados pela iconicidade presente na comunicação hipnótica. Decorre-se daí que, mesmo que a experiência vivida do sujeito seja a de um conflito, na qual se sente paralisado, oprimido ou esmagado, a fundamentação de primeiridade que também é presente em seu mundo inconsciente, colocam-no na possibilidade de um novo lugar nesta relação, pois ele, de certo modo, é também um representante deste universo (Colapietro, 1989). Assim, o acesso a esta base comum no nível do sentir, através do transe, permite o estabelecimento de uma relação distinta do eu frente a seu inconsciente, que também se modifica através do mesmo processo, de maneira que, do conflito, torna-se possível a construção da negociação, e da opressão, uma nova forma de reconciliação com o próprio mundo (Binswanger, 2008). De certa maneira, pode-se considerar que, de oprimido, o sujeito possa se voltar para este mundo e se apropriar de algo nele que também é seu, tornando-se um outro tipo de representante deste universo de conversações, encontros e acontecimentos coletivos.

Portanto, é possível tornar-se sujeito da própria vida e representante de diferentes pertencimentos (Morin, 2013) sem que isso implique num conflito insolúvel. Foi assim que, após lhe serem mostradas os diagramas que confirmavam a tônica negativa de sua vida, assim como seu provável destino funesto, Harvey se colocou numa posição de reflexividade, observando e pensando sobre tais processos, de onde lhe foi possível fazer novas opções para sua vida dali para frente. Contudo, tais opções só foram possíveis por conta de novas configurações que tornaram disponíveis outras qualidades de primeiridade que as fundamentassem e sustentassem ao longo do cotidiano de Harvey. Em uma palavra, o abandono do lugar de "saco de tristeza" constituiu-se em certa ruptura com os determinantes históricos, o que não deve significar um abandono absoluto de outros e novos processos inconscientes que se tornaram acessíveis. Sem eles como sustentação, suas mudanças não teriam como se manter em sua vida cotidiana.

\section{Considerações Finais}

Quando a obra e a imagem de um autor, como é o caso de Erickson, são tomadas para a construção de uma escola de psicoterapia, há uma série de consequências sociais e comunitárias no campo que podem, em muito, escapar aos intentos iniciais de seus fundadores. É indubitável que semelhante processo em torno de um mestre fundador, que garantiu em larga medida a ascensão e permanência das psicoterapias e, mais ainda, das ciências humanas (Stengers, 2013), talvez seja o que permita a sistematização da obra, sua visibilidade num dado campo, a atração de interessados e discípulos e a ocupação de espaços institucionais importantes. A obra se expande por meio de várias mãos de modo a enfrentar novos desafios e demonstrar sua pertinência frente a eles. É assim que, mesmo que Erickson não tenha sido o criador da terapia ericksoniana, é através deste nome que sua obra se difunde pelo mundo e seus diversos êxitos são altamente reconhecidos, principalmente no tocante à hipnose (CFP, 2001; Neubern, 2009).

No entanto, os movimentos em torno de um mestre fundador não raro apresentam-se problemáticos em função da tendência em diviniza-los, situando-os acima da esfera comum dos mortais e colocando-os como donos de uma capacidade genial e inalcançável de fazer clínica - em suma, uma capacidade irrepetível a outras pessoas e além das possibilidades de ser abordada pela pesquisa e pela reflexão. Semelhante forma de pensar, que se torna coletiva e influencia fortemente os mecanismos institucionais das escolas, é um dos passos mais típicos de um pensamento doutrinário (Morin, 2014), que se alimenta constantemente de suas origens ao mesmo tempo em que se enrijece em seus fundamentos e se fecha para um diálogo produtivo com o mundo. A espera messiânica de um novo gênio facilmente leva a um processo de degeneração que faz com que o que venha após ele nada mais seja que uma nota de rodapé de sua grande obra, obstando-se assim a uma perspectiva de progresso.

Isto porque, para que um pensamento evolua, não se deve propor, nem contar com a expectativa messiânica do aparecimento de um novo gênio, capaz de feitos tão grandes ou maiores que os do mestre fundador, mas deve-se buscar a capacidade de apropriação e reflexão coletiva dos adeptos, enquanto sujeitos de seus pensamentos, com suas possibilidades de criação pertinente frente a tais desafios. Dentre os vários tópicos necessários para a apreensão coletiva, destaca-se, exatamente, a pertinência das ideias que decorrem da obra do autor original que precisam ser colocadas como pauta das discussões coletivas. Tanto o revisitar de suas origens epistemológicas, tema comumente pouco aprofundado nas comunidades de psicólogos (Neubern, 2017), como aos aspectos conceituais que permitem um aprofundamento das relações entre clínica e pesquisa ocupam uma posição de considerável relevância nesse sentido, dado que ressaltam uma coerência entre as raízes desse pensamento e os problemas concretos encontrados na prática clí- 
nica de muitos terapeutas que simpatizam com tal proposta.

Dentro dessa perspectiva, a iconicidade apresenta uma considerável pertinência, num primeiro momento, por situar Erickson numa proximidade nada desprezível de uma de suas raízes epistemológicas - o pragmatismo norte-americano - ponto que raramente é discutido entre autores ericksonianos, que se limitam a associa-lo ao behaviorismo e ao cognitivismo, sem adentrarem em seus fundamentos epistemológicos (Neubern, 2009). Charles Peirce (citado em Colapietro, 1989), um dos autores pragmáticos mais relevantes da origem deste movimento, torna-se um nome pertinente para a discussão exatamente pela complexidade de seu trabalho, muito afim à obra de Erickson em diferentes pontos: o repúdio às noções clássicas de teoria, a singularidade dos sujeitos, o humanismo, a ruptura da dicotomia interno/externo na experiência, uma noção heterogênea de tecido subjetivo e a primazia dos processos de primeiridade, comumente além das deliberações do eu. Uma reflexão aprofundada nesse sentido liga epistemologia e clínica de modo bastante relevante, o que pode ser destacado em três questões.

Em primeiro lugar, ressalta-se o tecido semiótico que compõe a experiência hipnótica, no qual a iconicidade possui especial importância, e as formas de acessa-lo enquanto realidade. É possível conceber, ao menos inicialmente, que boa parte dos signos presentes nas alterações de referências do eu com o mundo constituam-se de formas que envolvam diagramas e metáforas, que propiciam a emergência de outros processos, principalmente ligados à primeiridade. No caso aqui discutido, a ênfase nos diagramas, construídos como eventos singulares neste processo, contrapõe-se a uma tendência comum de muitos terapeutas modernos para quem uma teoria geral (terceiridade) já serviria de base como leitura do que se passasse com ele. O conhecimento do outro, ou seja, uma questão epistemológica central (Neubern, 2017), faz-se por movimentos singulares na relação clínica que não devem induzir o terapeuta a uma conclusão geral e a-priori, mesmo que essa conclusão seja respaldada por pontos significativos trazidos pelo sujeito, como a metáfora depreciativa do "saco de tristeza".

Isto porque, se tais diagramas são representativos de uma narrativa dominante, eles também remetem a uma diversidade de processos semióticos configurados em sua experiência que escapam a seu domínio, de modo a promover mudança, particularmente pela potencialidade presente nos sentimentos não contemplados nesta narrativa. Ao mesmo tempo, os diagramas sustentam-se sobre uma realidade inefável, potencial e não concreta a dos sentimentos - que não pode ser apreendida como as demais por não ser um existente (Jappy, 2013), mas apenas de modo indireto, como se pode deduzir de alguns estudos sobre religião (Rambelli \& Reinders, 2014). A realidade em si desta primeiridade não pode, a bem dizer, ser apreendida, mas os dispositivos técnicos que lhe permitem a evocação e o acesso, calcados sobremaneira nos hipoícones
(Neubern, 2016a), podem ser descritos e compreendidos em suas possibilidades lógicas, epistemológicas e clínicas.

Em segundo lugar, a temporalidade se constitui como um dos temas mais significativos para a uma discussão coletiva, notadamente por sua associação aos processos históricos dos sujeitos. A perspectiva de Erickson (Erickson \& Rossi, 1980), fugindo da lógica causalista e determinista do passado dominante em outras escolas (Gonzalez Rey, 2007), destaca a dimensão de vivência na qual tanto o passado quanto futuro podem ser presentificados na experiência vivida dos sujeitos, como sustentado em algumas propostas existencialistas européias (Binswanger, 2008; Minkowski, 2014).

Contudo, a proposta de iconicidade calcada na ótica de Peirce (citado em Nöth, 2015), traz a significativa contribuição de relacionar a temporalidade aos signos ali expressos no processo hipnótico (principalmente os hipoícones) à experiência dos sujeitos. De um ponto de vista epistemológico, trata-se de uma realidade vivida na qual presente, passado e futuro encontram-se entrelaçados por meio de seus signos, o que permite, através das potencialidades lógicas destes signos (Bergman, 2009), a compreensão sobre a experiência temporal dos sujeitos. Embora Harvey tivesse seu futuro, a bem dizer, bloqueado por uma provável tragédia, iniciou seu movimento de mudança quando, em transe, materializou no presente sua experiência negativa passada por meio de diagramas, o que se fez possível devido ao papel da primeiridade, que essencialmente se constitui no presente. Numa realidade tão complexa quanto esta, se o diagrama presentifica o passado, as metáforas dispõem o sujeito ao futuro, uma vez que compõem o que poderia ser considerado como "leis simbólicas e emocionais do sujeito" (Lakoff \& Johson, 2003; Schore, 2016) ou, simplesmente, seus hábitos (Nöth, 2015).

De certo modo, é possível conceber que, pela hipnose, o trabalho neste nível metafórico da subjetividade permite o acesso a dimensões profundas da própria identidade do sujeito, onde tais metáforas se configuram e situam o sujeito frente a si, aos outros e ao mundo (Gonzalez Rey, 2007). Entretanto, no tocante aos hipoícones, a construção do transe se constitui tanto por diagramas (que fixam a atenção), como por imagens, já que, comumente, é pelo contato mais intenso e pleno com o presente que se desenvolvem as alterações de referências, chamadas como processos dissociativos pelos hipnoterapeutas (Bioy, 2017; Zeig, 2014). Como na terapia de Harvey, a fixação de atenção nas cenas envolveu diversos diagramas (como as próprias cenas, mas também as sugestões do terapeuta para que ele as olhasse), mas foi a partir dessa novidade inefável do agora que seus processos de mudança começaram a ser desenhados.

Em terceiro lugar, as relações do eu com as influências inconscientes se constituem como importante questão de interesse ao debate coletivo. Isto porque a própria hipnose de Erickson (Erickson \& Rossi, 1980) aponta um jogo complexo entre as determinações diversas na constituição do sujeito e os 
processos de criação e reinvenção que caracterizam sua autonomia (Neubern, 2016b). Nesse sentido, a semiótica parece apontar para esta duplicidade, tanto ao ressaltar o eu como uma forma semiótica que remete a uma gama de conversações anteriores, como os diferentes momentos de criação que caracterizam a semiose (Colapietro, 1989). É assim que a construção de uma identidade negativa remeteu a uma gama de pautas relacionais significativas e depreciativas de vida de Harvey que fizeram com que ele atuasse e concebesse os eventos da vida, ou seja, como um protagonista, dentro de seus determinismos negativistas. Contudo, ao se esboçarem as mudanças, este eu teve um papel ativo em suas novas ações e escolhas, também amparado por outras qualidades afetivas mobilizadas pelo transe.

Nesse sentido, a experiência do transe parece fazer emergir uma infinidade de signos e processos de semiose que pareciam estar inativos ou possuíam pouco alcance na subjetividade da pessoa, trazendo à tona considerações de grande relevância sobre a autonomia ou agenciamento também presentes em processos inconscientes (Gallagher, 2012). Disso resulta tanto conceber que essas conversações que antecedem o eu são mais diversas e polifônicas do que costumam aparentar e que a subjetividade de cada um consiste num grande palco, no qual diferentes formas semióticas protagonizam as mais diversas formas de relação, como o conflito, o diálogo, a escravização, o comércio, o contrabando e a solidariedade (Morin, 2013). Isso permite conceber um processo terapêutico como o de Harvey como uma arena de negociação, na qual outras formas semióticas entrariam em cena e o eu pudesse assumir novas inserções neste mundo, como no mundo social.

A conversação do terapeuta com o sujeito em transe aproxima-se muito da semiose que tem lugar na subjetividade deste último, o que parece apontar para uma forma muito peculiar de iconicidade. Quando Erickson pediu a Harvey que analisasse aquelas cenas e pensasse em suas implicações, parecia estar já dentro de seu mundo, dadas as alterações de referências típicas do transe. Isso parece fazer com que a figura do terapeuta faça uma espécie de duplo ao eu do sujeito (Morin, 2013), para que este possa assumir esta voz temporariamente até encontrar sua própria voz nesta negociação. A própria ligação emocional que ali acontece pode favorecer que este momento clínico, enquanto conversação, acrescente algo de significativo na forma semiótica do eu do sujeito. Esta, porém, como os demais pontos acima, é apenas uma ideia inicial que demandará novas pesquisas e aprofundamentos para ser melhor compreendida.

\section{Referências}

Bergman, M. (2009). Peirce's philosophy of communication. New York: Continuum.

Binswanger, L. (2008). Introduction à l'analyse existentielle. Paris: Puf.
Bioy, A. (2017). Présences. In A. Bioy \& T. Servillat (Orgs.). Construire la communication thérapeutique avec l'hypnose (p.79-94). Paris: Dunod.

Brito, O., \& Pesce, S. (2015). De la recherche qualitative à la recherche sensible. SpécifiCITéS. Paris : Champ Social.

CFP (2001). Jornal do Conselho Federal de Psicologia, 67, resolução CFP no. 013/00 de 20/12/2000, p. 7.

Clément, C. (2011). L'appel de la transe. Paris: Stok.

Colapietro, V. (1989). Peirce's approach to the self. New York: Suny.

Erickson, M., \& Rossi, E. (1980). The colletcted papers of Milton H. Erickson, MD (8 vols). New York: Irvington.

Erickson, M., \& Rossi, E. (1981). Experiencing hypnosis. New York: Irvington.

Gallagher, S. (2012). Multiple aspects of agency. New Ideas in Psychology, 30, 15 - 31.

Ginot, E. (2015). The neuropsychology of the unconscious. London: Norton \& Company.

Gonzalez Rey, F. (2007). Psicoterapia, subjetividade e pós-modernidade. São Paulo: Thomsom.

Jappy, T. (2013). Introduction to peircean visual semiotics. New York: Bloomsbury.

Jensen, M., \& Patterson, D. (2014). Hypnotic approaches for chronic pain management. American Psychologist, 2, $167-177$.

Lakoff, G., \& Johnson, M. (2003). Metaphors we live by. Chicago: University of Chicago Press.

Minkowski, E. (2014). Le temps vécu. Paris: Puf. (Obra original publicada em 1933).

Morin, E. (2013). La méthode V. L'humanité de l'humanité. Lidentité humaine. Paris: Seuil.

Morin, E. (2014). La méthode IV. Les idées. Paris: Seuil.

Nathan, T. (2015). Nous ne sommes pas seuls au monde. Paris: Seuil/Synthélabo.

Neubern, M. (2009). Psicologia, hipnose e subjetividade. Belo Horizonte: Diamante.

Neubern, M. (2014). Subjetividade e complexidade na clínica psicológica: superando dicotomias. Fractal, Revista de Psicologia, (26), 3, 835 - 852.

Neubern, M. (2016a). Iconicidade e complexidade na comunicação hipnótica. Psicologia: Teoria e Pesquisa, 32 (esp), $1-9$.

Neubern, M. (2016b). Hipnose clínica e dores crônicas: rumo a uma perspectiva complexa. Psicologia em Estudo, 21 (2), $303-312$. 
Neubern, M. (2017). Contribuições da hipnose para a pesquisa qualitativa. Psico-USF, 22 (2), 361 - 370.

Nöth, W. (2012). Charles S. Peirce's theory of information: a theory of the growth of symbols and of knowledge. Cybernetics and Human Knowing, 19 (2), 137 - 161.

Nöth, W. (2015). The paradigms of iconicity in language and literature. In M. Hiraga (Org). Iconicity: east meets west. (pp. 13 - 34). Amsterdan: John Benjamins.

Peirce, C. (1998). The essential Peirce. Indianapolis: Indiana University Press.

Rambelli, F., \& Reinders, E. (2014). Buddhism and iconoclasm in East Asia. London: Bloomsbury.

Scheschner, R. (2013). Performance studies. An introduction. London: Routledge.

Schore, A. (2016). Affect regulation and the origin of the self. New York: Routledge.

Stengers, I. (2013). L'invention des sciences modernes. Paris: Flammarion.

White, M. (2007). Maps of narrative practice. New York: Norton.

Zeig, J. (2014). The induction of hypnosis. Phoenix: Milton Erickson Foundation Press.

Maurício S. Neubern é Doutor em Psicologia e Professor Adjunto da Universidade de Brasília (UnB). Endereço para Correspondência: Universidade de Brasília, Campus Darcy Ribeiro, ICC Sul, Instituto de Psicologia, Departamento de Psicologia Clínica. CEP 70910-900, Brasília, DF, Brasil. Email: mauricio.neubern@gmail.com

Hugo Nogueira Gonçalves é Mestrando do Programa de Pós-Graduação em Psicologia Clínica e Cultura da Universidade de Brasília. Possui graduação em Psicologia pela Universidade de Brasília.

Recebido em: 15.01.2018

Primeira Decisão Editorial: 19.04.2018

Aceito em: 25.04.2017 